\title{
Electrical Characterization of Hybrid Halide Perovskites Based Heteroj unction Device*
}

\author{
(C) Jyoti Chaudhary ${ }^{1}$, Shaily Choudhary ${ }^{1}$, Chandra Mohan Singh Negi ${ }^{2}$, \\ Saral K. Gupta ${ }^{1}$, Ajay Singh Verma ${ }^{1, \uparrow}$ \\ ${ }^{1}$ Department of Physics, Banasthali Vidyapith, \\ Banasthali 304022, India \\ ${ }^{2}$ Department of Electronics, Banasthali Vidyapith, \\ Banasthali 304022, India \\ I E-mail: aiav phv@rediffmail.com \\ (Received October 17, 2018 \\ Revised November 11, 2018 \\ Accepted November 11, 2018)
}

Herein, we have measured the mobility of Hole's for the configuration $\mathrm{FT} 0 / \mathrm{TiO}_{2} / \mathrm{CH}_{3} \mathrm{NH}_{3} \mathrm{PbBr} 3 / \mathrm{PCBM} / \mathrm{Al}$ by the SCLC regime. The current-voltage (I-V) characteristics of the $\mathrm{CH}_{3} \mathrm{NH}_{3} \mathrm{PbBr}_{3}$ perovskite based device shows the rectifying behavior as Schottky diode. Different parameters of the proposed device such as saturation current, ideality factor, barrier height have been taken out from I-V characteristics. The highest Hole's mobility from $\mathrm{Ti}_{2}$ thin film through the perovskite and PEDOT:PSS film to the top aluminum electrode has of order $1.59 \cdot 10^{-4} \mathrm{~cm}^{2} \mathrm{~V}^{-1} \mathrm{~s}^{-1}$. Moreover, the proposed device shows the TFSCLC regime at lower voltage while, at higher voltages it shows the TCLC regime. In addition to this, some important parameters like junction resistance, capacitance and carrier lifetime of device can be measured by the spectroscopy analysis of impedance.

DOI: 10.21883/FTP.2019.04.47448.9006

* Полный текст статьи опубликован в переводной версии журнала „Физика и техника полупроводников“ — SEMICONDUCTORS (T. 53. Вып. 4). 